\title{
O REAL PELO VIÉS DA PONTUAÇÃO
}

\section{PATRÍCIA LAUBINO BORBA RODEGHER ${ }^{1}$}

\author{
Católica EAD \\ Universidade Católica de Brasília \\ SGAN 916 Módulo B - Brasília - DF - 70.790.160 \\ patricia.borba.rodegher@gmail.com
}

\begin{abstract}
Resumo. O presente artigo apresenta a noção de tangenciamento do real. Essa noção é demonstrada pelo ato de pontuação. A análise é feita a partir de dois textos de um paciente psicótico participante de uma oficina de escrita realizada em um Centro de Atenção Psicossocial. O objetivo do artigo é compreender a irrupção de efeito de não-sentido no texto do psicótico e o funcionamento discursivo subjacente a esse efeito. Para isso, pesquisamos a noção de real tanto na Psicanálise quanto na Análise do Discurso de Michel Pêcheux. Examinamos a noção de pontuação, tanto na Teoria Enunciativa, quanto na Psicanálise e na Análise do Discurso. E, por último, estudamos o funcionamento discursivo do tangenciamento do real na pontuação dos textos mencionados.
\end{abstract}

Palavras-chave: Discurso; Pontuação; Análise do Discurso; Psicanálise; Psicose.

\begin{abstract}
This paper presents the concept of tangency of the real. This notion is demonstrated through the act of punctuation. The analysis is based on two texts of a psychotic patient who attended a writing workshop held at a Psychosocial Care Center. The purpose of the study is to understand the irruption of the non-sense effect in the psychotic's text and the discursive functioning underlying this effect. To this end, we researched the perceptions of real in both Psychoanalysis and Michel Pêcheux's Discourse Analysis. We have examined the notion of punctuation, in enunciative theory, as well as in Psychoanalysis and Discourse Analysis. Finally, we have studied the discursive mechanism of the tangency of the real in the punctuation of the referred texts.
\end{abstract}

Keywords: Discourse; Punctuation; Discourse Analysis; Psychoanalysis; Psychosis.

\footnotetext{
${ }^{1}$ Doutora em Linguística pela Universidade Federal do Rio Grande do Sul. Discente na Universidade Católica de Brasília.
} 


\section{INTRODUÇÃO}

No presente artigo, estudaremos o real a partir do funcionamento da pontuação. Para pensar a questão da linguagem e do real foi necessário forjar o conceito de tangenciamento do real que trata da tentativa sempre malsucedida de simbolizar o real. Essa propriedade de tangenciar o impossível de ser simbolizado só se realiza pela junção entre língua, ideologia e inconsciente.

Propomos analisar, nesse trabalho, uma materialidade discursiva não prevista pelos estudos clássicos da Análise do Discurso: os textos de pacientes psicóticos. Acreditamos ser possível incluir essa materialidade nos estudos da Análise do Discurso porque os textos dos psicóticos são atravessados por duas noções caras a essa área de estudo: a ideologia e o inconsciente (BORBA-RODEGHER, 2011).

Os textos utilizados para a análise pertencem a um paciente psicótico que participa do grupo terapêutico denominado "Atelier de Escrita", que se reúne no Centro de Atenção Psicossocial (CAPS) Região Centro de Porto Alegre, RS. O paciente escrevia textos uma vez por semana na oficina de escrita. A leitura e cópia dos textos foram feitas sob a autorização do paciente e da Secretaria Municipal de Saúde da Prefeitura de Porto Alegre. Para analisarmos como ocorre o tangenciamento do real nos textos do paciente é preciso primeiro estudarmos a noção de psicose. O levantamento bibliográfico desta noção nos permitirá compreender como a subjetividade pode contribuir para os estudos discursivos a respeito do funcionamento da língua.

Para Lacan (1957- 1958), a psicose ocorre por um acidente na estruturação da linguagem, devido ao fracasso do psicótico em atravessar os momentos lógicos do Édipo. Como na psicose a clivagem não ocorreu, o inconsciente está a "céu aberto".

Em "A perda da realidade na neurose e na psicose" (1924), Freud mostra que na psicose, a fuga da realidade é sucedida por uma remodelagem por meio do delírio. $\mathrm{O}$ delírio é executado sobre os restos da antiga relação que o ego estabelecia com a realidade, ou seja, sobre "os traços de memória, as ideias e os julgamentos anteriores derivados da realidade e através dos quais a realidade foi representada na mente [do paciente psicótico]" (FREUD, 1924, p. 207).

As alucinações sustentam a realidade criada pelo ego, pois fornecem uma confirmação de sua existência. O delírio é visto por Freud (1924) como uma cura espontânea por parte do paciente, pois tem a função de restaurar a realidade perdida. $\mathrm{O}$ delírio está na dependência do inconsciente. A alucinação é o aparecimento no real daquilo que foi rejeitado no simbólico.

$\mathrm{Na}$ psicanálise lacaniana, o real resiste a ser simbolizado. Essa noção está relacionada à repetição, na medida em que o real é o que retorna sempre ao mesmo lugar. $\mathrm{O}$ inconsciente e o real são categorias coextensivas. As relações que se estabelecem a partir dessas duas noções estão em seus valores negativos ("sem-sentido", "não-sentido").

O real, na Psicanálise lacaniana, é um dos registros que constituem o aparelho psíquico, tal como o imaginário e o simbólico. $\mathrm{O}$ real é anterior à linguagem. "O real é [...] o que retorna sempre ao mesmo lugar - a esse lugar onde o sujeito, na medida em 
que ele cogita, [...] não o encontra. (LACAN, 1998 [1964], p. 52). O real se relaciona com a linguagem e é buscando compreender essa relação que desenvolvemos a noção de tangenciamento do real; ou seja, o funcionamento da pontuação é a base linguístico discursiva para compreender a relação entre real e linguagem. Estudaremos a noção de real tanto na Psicanálise quanto na Análise do Discurso.

\section{O REAL NA PSICANÁLISE E NA ANÁLISE DO DISCURSO}

Para estudarmos o tangenciamento do real no discurso do psicótico lançamos mão da teoria da Análise do Discurso. Essa teoria concebe também uma noção de real que se assemelha à de Lacan, na medida em que comporta o conceito de impossível. Porém, na psicanálise, pensa-se o real como constituinte do aparelho psíquico. Ao passo em que Pêcheux reflete a respeito da impossibilidade do real em vários níveis: real da língua, real da história e real do inconsciente. O real em Pêcheux (1981) abarca a condição de existência das noções, ou seja, o que é próprio, o que é da natureza da noção em questão, o que é impossível que seja de outro modo. Em nosso trabalho, utilizamos as noções de real em Lacan e Pêcheux de formas distintas. Enquanto a primeira é objeto de descrição no discurso do psicótico, a segunda é o que permite realizarmos essa descrição.

Outra noção que utilizamos em nossa análise é de alingua, porque ela nos permite compreender como ocorre o tangenciamento do real. Jacques Lacan (1973), no Seminário 20, Mais ainda, aproxima as noções de linguagem e inconsciente para formular a noção de alíngua. Para Lacan (1973), a linguagem não existe, é apenas uma construção teórica proveniente do discurso científico, forjada para dar conta daquilo que existiria de fato, alíngua. Se a noção de linguagem está vinculada à de comunicação, a noção de alíngua está relacionada à de inconsciente: "Alíngua serve para coisa inteiramente diferente da comunicação. É o que a experiência do inconsciente mostrou, no que ele é feito de alíngua" (1973, p. 188). Ao formular a noção de alíngua, Lacan nos mostra outro conceito de linguagem na medida em que ela carrega consigo outras questões que não dizem respeito à comunicação: "A linguagem, sem dúvida, é feita de alíngua". (LACAN, 1973, p. 190). Lacan sintetiza a relação que haveria entre as noções linguagem, alíngua e inconsciente na seguinte formulação: "A linguagem é um saber sobre alíngua e o inconsciente é um saber-fazer com a alíngua" (1973, p. 190).

A noção de alíngua repercute na Linguística, através de um desdobramento dessa noção formulado por Milner (1987) em Amor da língua. Nessa obra, o autor retoma a formulação de Lacan (alíngua) e desenvolve a questão por ele apontada: a existência de uma construção teórica sobre linguagem - e sobre a língua, acrescenta Milner - que excluiria alíngua do discurso científico. Para o linguista, alíngua é tanto uma língua entre outras, quanto o registro consagrado ao equívoco em todas línguas (MILNER, 1987, p. 15). Milner nos mostra que é necessário que alíngua seja excluída de todas as línguas, para que essas possam ser percebidas como unas, homogêneas e formais, e assim responderem a uma demanda universalizante que as agrupe em uma só classe. Porém, fora do campo da reflexão teórico-científica, a língua manifesta cotidianamente a sua equivocidade, através dos chistes, ambiguidade, homofonias, homossemias, homografias, etc. Essas manifestações negam à língua a característica de identidade, homogeneidade e formalidade. Ou seja, apesar de a língua ser uma construção teórica que afastaria a 
questão da equivocidade, ela suporta o lugar da impossibilidade do dizer que há na noção de alíngua, porque é na língua que alíngua manifesta a tentativa de apreender o real.

O real é impossível de ser capturado, porém isso não inviabiliza o seu tangenciamento realizado por alíngua, pois, como já mencionamos, "o inconsciente é um saber-fazer com alíngua". A aproximação entre as noções de alíngua, inconsciente e real ocorre magistralmente nessa formulação milneriana que nasce de uma apropriação do texto de Lacan (1973): "alguma coisa não cessa de não se escrever aí" (MILNER, 1987, p. 25). Ou seja, é o real que resiste a ser simbolizado, mas que ao mesmo tempo não pode deixar de se marcar. Essa construção em alíngua só é possível pelo "fazer" do inconsciente. Milner traz a poesia como exemplo dessa construção:

o surpreendente é que o fracasso não seja absoluto e que um poeta se reconheça nisso que ele consiga efetivamente, senão preencher a falta, ao menos afetá-la. Na alíngua, que ele trabalha, acontece que um sujeito imprima uma marca e abra uma via onde se escreve um impossível a escrever (MILNER, 1987, p. 26).

Leite (1994, p. 71) reformula muito bem as reflexões de Milner: "a escrita da impossibilidade, vale dizer, a impossibilidade demonstrada". Em nosso trabalho, queremos compreender como esse fazer em alíngua reflete-se na língua: porém, compreenderemos a língua não apenas afetada pelo inconsciente, mas também sujeita à ideologia.

Para compreendermos a injunção do real na escrita psicótica, teremos que inicialmente analisar os vínculos que Psicanálise e Análise do Discurso estabelecem, a fim de investigar como os estudos discursivos podem ajudar a compreender a questão do real.

Pêcheux sofre influência da Psicanálise lacaniana ou como formula Plon (2007), "tudo parece ter-se passado como se Michel Pêcheux tivesse entendido bem alguma coisa de essencial procedente da Psicanálise lacaniana" (PLON, 2007, p. 41). Porém, é preciso ressaltar que não se trata de uma transferência de conceitos lacanianos para a Análise do Discurso, mas de uma apropriação seguida de reformulação de questões da Psicanálise que são relevantes para pensar noções como discurso, sujeito, sentido etc.

As noções de alíngua e de real também ecoam na Análise do Discurso. Pêcheux reformula a noção de real de Lacan, refletindo sobre a relação entre o discurso e o objeto não discursivizado: "Supor que [...] há independência do objeto face a qualquer discurso feito a seu respeito, significa colocar que, no interior do que se apresenta como o universo físico-humano [...] 'há real', isto é, pontos de impossível, determinando aquilo que não pode não ser 'assim"' (PÊCHEUX, 1983, p. 29). A questão da impossibilidade que está na noção de real de Lacan (1998 [1964]) é mantida no conceito de real da Análise do Discurso, porém, a esta é agregada a ideia de propriedade intrínseca: "o real é o impossível ... que seja de outro modo" (PÊCHEUX, 1983, p. 29)2.

\footnotetext{
${ }^{2}$ Real como impossível é formulado por Lacan (1998 [1964], p. 159). A segunda parte da citação de Pêcheux faz parte da reformulação.
} 
A noção de real da língua, em Gadet e Pêcheux (1981), pressupõe a noção de alíngua de Lacan e Milner. O real da língua

é cortado por falhas, atestados pela existência do lapso, do Witz e das séries associativas que o desestratificam sem apagá-lo. O não-idêntico que aí se manifesta pressupõe a alíngua, enquanto lugar em que se realiza o retorno do idêntico sob outras formas; a repetição do significante na alíngua não-coincide com o espaço do repetível e que é próprio à língua, mas ela o fundamenta e, com ele, o equívoco que afeta esse espaço: o que faz com que, em toda língua, um segmento possa ser ele mesmo e um outro, através da homofonia, da homossemia, da metáfora, dos deslizamentos do lapso e do jogo de palavras, e do bom relacionamento entre os efeitos discursivos (GADET; PÊCHEUX, 1981, p. 55).

Utilizamos a noção de real da língua para pensar na propriedade da língua de tangenciar o impossível. Deparamo-nos com este tangenciamento na dicotomia "certo e errado" formulada pela gramática, nos enunciados mal formulados decorrentes da gagueira e da afasia, e na fala sintomática numa seção psicanalítica. Porém, o tangenciamento também pode se manifestar na ordem do discurso e, dessa forma, o nonsense pode surgir num discurso político, religioso, midiático, virtual, médico, pedagógico.

O tangenciamento do real se torna possível a partir da junção entre língua, ideologia e inconsciente. A distinção entre as noções de alíngua e real da língua está na inclusão da questão da ideologia nessa segunda: "a questão da materialidade histórica é o ponto em que nos separamos politicamente de Milner" (GADET; PÊCHEUX, 1981, p. $52)$.

A noção de real de Pêcheux se assemelha a de Lacan na medida em que comporta o conceito de impossível. Porém, na psicanálise pensa-se o real como constituinte do aparelho psíquico, enquanto Pêcheux, na noção de real, reflete a respeito da impossibilidade (que seja de outro modo) em vários níveis. Em "Matérialités Discursives", o analista de discurso afirma: "Il y a un réel de la langue. Il y a un réel de l'histoire. Il y a un réel de l'inconscient" (PÊCHEUX, 1981, p. 143).

A noção de real de Pêcheux difere da de Lacan na medida em que abarca a condição de existência do real, ou seja, o que lhe é próprio, o que pertence a sua natureza. Esta noção de real é muito produtiva na Análise do Discurso, pois pode ser pensada em várias instâncias: real da língua (equívoco), real do sujeito (inconsciente), real da história (contradição), real do discurso (silêncio), real do sentido (incompletude).

Se pensarmos a intersecção dos reais $^{3}$ citados podemos compreender a possibilidade da metáfora e do deslocamento pensados como mecanismos de constituição discursiva. A seguir, faremos a intersecção dos reais utilizando o Nó Borromeano para ilustrar nossa reflexão:

\footnotetext{
${ }^{3}$ A percepção de real no plural só pode ser pensada em Pêcheux, para Lacan o real sempre estará no singular.
} 


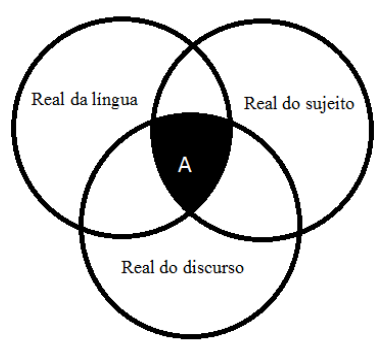

Figura 1: Intersecção dos reais da língua, sujeito e discurso.

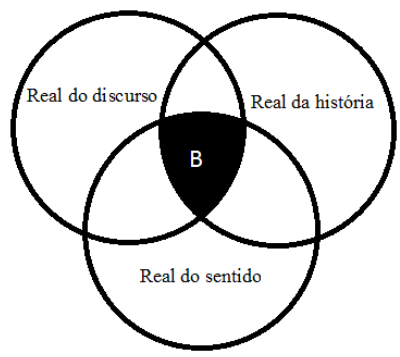

Figura 2: Intersecção dos reais do discurso, da história e do sentido.

É a partir da intersecção das noções de equívoco, inconsciente, silêncio, contradição e incompletude que podemos pensar a possibilidade de o discurso ser uma estrutura que comporta o acontecimento. A metáfora e o deslocamento no discurso só podem ser concebidos se compreendemos que o real do discurso se intersecciona tanto com o real do sujeito e o real da língua (A - Fig. 1), quanto o real da história e o real do sentido (B - Fig. 2).

Em uma passagem de A língua Inatingível, Gadet e Pêcheux (1981) afirmam que "a linguística encontra seu real no ponto em que ela relaciona-se com a psicose" (GADET; PÊCHEUX, 1981, p. 47). A linguística é uma ciência em que há pouca reflexão sobre linguagem em subjetividade diferente da neurótica, como é o caso da psicose e de patologias de linguagem. Do que ela se protege ${ }^{45}$

\section{PONTUAÇÃo}

A fim de analisar o tangenciamento do real no ato de pontuação, estudamos a noção de pontuação em algumas teorias.

\footnotetext{
4 "De quoi nous protégeons-nous, en nous déclarant linguistes, historiens, ou psychanalystes?" (PÊCHEUX, 1981, p. 143).
} 
Chacon (1998), a partir de uma perspectiva enunciativa, compreende a pontuação como uma das formas de estabelecimento do ritmo na linguagem. O ritmo, na perspectiva desse autor, opera na construção da subjetividade: "O ritmo é subjetivo não no sentido de que ele reflete tais sentimentos e emoções, mas no sentido de que ele lhes dá forma" (CHACON, 1998, p. 31). O ritmo tem o papel de organizar o fluxo enunciativo: "o ritmo organiza o heterogêneo do discurso na atividade enunciativa" (CHACON, 1998, p. 39). O ritmo em Chacon (1998) não pode ser confundido com a métrica:

\begin{abstract}
A regularidade métrica não possibilita explicar a alternância rítmica do sujeito na enunciação, já que, produzida pela ameaça e inscrição do outro, essa alternância ocorre entre aquelas estruturas linguísticas que tentam colmatar a presença do outro em momentos não necessariamente regulares do fluxo do discurso. A não-regularidade da presença do outro produz, portanto, na cadeia discursiva, unidades rítmicas (correlativas às formas de colmatação) de estrutura e extensão variadas e variáveis, diretamente vinculadas à produção do sentido no discurso - aspecto da linguagem que a métrica também exclui (CHACON, 1998, p. 39).
\end{abstract}

A pontuação também é um tema relevante na Psicanálise. Como nos ensina Darman (1997, p. 133-134), numa sessão psicanalítica, a escansão realizada pelo analista no dizer do analisando é um tipo de pontuação. Darman a distingue daquela realizada pelo escrevente em seu texto. $\mathrm{O}$ analista pontua em função da abertura e do fechamento do inconsciente, dos lapsos, dos atos falhos etc. A pontuação do analista não força o fim de uma frase, nem ocorre na sequência de um desenvolvimento: ela é feita sobre um significante que se faz entender à revelia do sujeito. Essa pontuação tem como objetivo estabelecer um corte e, desse modo, fazer surgir um efeito de sentido que rompa com o sentido manifesto no discurso do analisando. Como explica o autor: "il y a un lien étroit entre coupure et effet de sens. Ces coupures ne se confondent pas avec les pauses, avec des interruptions de la chaîne parlée, mais elles s'établissent plutôt rétroactivement" (DARMAN, 1997, p. 134) ${ }^{6}$. Como vimos, Darman (1997) nos mostra que a noção de pontuação vinculada à psicanálise é diferente daquela produzida no texto, porém, acreditamos que as duas produzem efeitos de sentido. A pontuação na escrita delimita unidades de sentido provenientes do interdiscurso, a pontuação na psicanálise apreende significantes no inconsciente.

O autor também nos ensina que "il n'y a pas de ponctuation au niveau de l'inconscient proprement dit" (DARMAN, 1997, p. 138) ${ }^{7}$, e, para nos fazer entender isso, associa o conceito de inconsciente à ideia de conjuntos da matemática: "l'inconscient comme assemblages de lettres. Et la pratique analytique consiste à conduire le sujet à se retrouver dans ces assemblages, c'est-à-dire dans son savoir inconscient et à partir de là à prendre ses responsabilités" (DARMON, 1997, p. 139-140) ${ }^{8}$.

Percebemos, durante a leitura do nosso arquivo, que as teorias tanto a linguística quanto a psicanalítica até aqui apresentadas não dão conta de explicar a complexidade da

\footnotetext{
${ }^{6}$ Tradução: Existe uma ligação estreita entre o efeito de corte e o sentido. Esses cortes não são confundidos com pausa, com interrupções da fala, mas eles se estabelecem de forma retroativa.

${ }^{7}$ Tradução: Não há pontuação ao nível do inconsciente propriamente dito.

${ }^{8}$ Tradução: O inconsciente como um conjunto de letras. E a prática analítica é levar o sujeito a se encontrar nesse conjunto, isto é, em seu conhecimento inconsciente, e, a partir daí, assumir sua responsabilidade.
} 
pontuação do paciente psicótico. Nosso objetivo, no presente trabalho, é pensar como a pontuação nos textos estudados reflete a relação da psicose com o sentido.

Para analisar isso, é necessário compreender a pontuação como uma materialidade discursiva e, assim, refletir a respeito de seu caráter linguístico, histórico, social e inconsciente. Filiamo-nos à Análise do Discurso, por compreender que essa teoria consegue dar conta desses aspectos da pontuação. Não iremos excluir das nossas análises reflexões sobre o viés enunciativo e psicanalítico: porém, incluiremos em nossa reflexão aquilo que essas teorias não comportam: a questão da ideologia.

Orlandi (2005), como os gramáticos, relaciona a noção de ritmo à pontuação. Porém, diferentemente daqueles que vinculam a pontuação à sonoridade e à pausa, a autora opacifica a ideia de batimento subjacente ao conceito de ritmo, ou seja, "a pontuação faz parte da marcação do ritmo entre o dizer e o não dizer" (ORLANDI, 2005, p. 111). A pontuação é o vestígio no texto da relação de unidade e dispersão, que é inerente ao texto. $\mathrm{O}$ texto produz um efeito de unidade que é sua característica principal como texto, mas, ao mesmo tempo, nasce do interdiscurso e a ele sempre se remete. A pontuação apaga a relação do texto com o interdiscurso e, contraditoriamente, denuncia essa relação.

Para Orlandi (2005), a pontuação é "o lugar em que o sujeito trabalha seus pontos de subjetivação, o modo como ele interpreta" (ORLANDI, 2005, p. 110). Pontuar é um gesto de interpretação, na medida em que "seleciona" saberes do interdiscurso, produzindo um efeito de unidade e homogeneidade, que permite "um ajuste na relação discurso e texto" (ORLANDI, 2005, p. 113). Dessa forma, a pontuação também é um vestígio do assujeitamento, que é pressuposto para a interpretação, como nos ensina Calil (2004): "É porque se está assujeitado que se pode romper. Em outras palavras, é do repetível (já dito) que advém o deslocamento para o inesperado" (CALIL, 2004, p. 44).

A pontuação também marca no texto a interlocução: "Se a ordem do discurso efeito de sentido entre locutores - se materializa no texto, materialização de que a organização textual é o vestígio, em nosso caso, esses vestígios são a pontuação" (ORLANDI, 2005, p. 114). A pontuação administra a relação do sujeito com a incompletude, a falha e o equívoco da linguagem, "trabalhando a incompletude do sentido e o inacabamento do sujeito" (ORLANDI, 2005, p. 116). O trabalho da pontuação é assegurar uma "normalidade" semântica na materialidade textual.

A autora identifica dois modos de pontuação. O primeiro ocorre na dimensão da frase (vírgula e travessão). Esse modo "abre, em seu interior, um espaço em relação ao Outro" (ORLANDI, 2005, p 111). O segundo ocorre além da frase (ponto, dois pontos e reticências). Esses sinais de pontuação "trabalham os limites impossíveis em relação a um fora inacessível, inapreensível, inatingível” (ORLANDI, 2005, p. 111). Estudaremos apenas um sinal de pontuação de cada modo, a saber, a vírgula e o ponto final, porque são esses os mais significativos no arquivo estudado. A vírgula é definida por Orlandi (2005) como "signo da des-ligação em relação ao interdiscurso, fazendo intervir a passagem para outro discurso, abrindo para outro sentido" (ORLANDI, 2005, p. 117). A vírgula, ao mesmo tempo em que rompe com a dispersão e a heterogeneidade do interdiscurso, abre espaço para outro saber. $\mathrm{Na}$ enumeração, a vírgula é uma marca de que outros elementos virão. Já nas orações explicativas, é a sinalização de um acréscimo. 
O ponto final delimita o sentido, na medida em que "exclui o que não está lá" (ORLANDI, 2005, p. 117).

Na perspectiva da Análise do Discurso, Lisbôa (2008) nos mostra a utilização criativa da pontuação realizada por Clarice Lispector. Essa criatividade ocorre por meio da transgressão das regras de pontuação oriundas da gramática e desembocando em novos efeitos de sentido. Dessa forma, Lispector

usa, por exemplo, para delimitar a frase, minúsculas ao invés de maiúsculas; usa, ainda vírgula e dois pontos, que são delimitadores de partes das frases, no início e no final do romance, respectivamente, como [...] no caso de "Uma aprendizagem ou livro dos prazeres; usa signos que tem por função interromper a progressão normal da frase, como o travessão, para iniciar e encerrar um romance, como é o caso de “A paixão segundo GH”. (LISBÔA, 2008, p. 97)

Para Lisbôa (2008), a pontuação é um lugar privilegiado para observar a noção de silêncio (formulada por Orlandi (1992)): "Trabalhando os espaços de silêncio da linguagem, Clarice Lispector faz com que o leitor, através de uma pontuação peculiar, seja lançado no interdiscurso ou no próprio silêncio, real do discurso, onde todo dizer é possível, e busque, aí, os seus sentidos" (LISBÔA, 2008, p. 95). Outro ponto importante na reflexão de Lisbôa é que a pontuação em Lispector tem "mais uma função desorientante da significação do que propriamente de orientação [...] Clarice joga o leitor, pela via da pontuação, neste silêncio, onde a iminência do sentido se encontra com o indizível" (LISBÔA, 2008, p. 97). Porém, essa desorientação produz efeitos de sentido, como Lisbôa ressalta, possibilitando assim ou o preenchimento de sentidos pelo leitor (LISBÔA, 2008, p. 101), ou o lançamento do leitor para o "campo do indizível" (idem, p. 104).

Lisbôa (2008) cria a noção de labuta da obra de Lispector para chegar a determinados efeitos de sentido pela pontuação. A pontuação nos textos de Clarice surge de uma labuta da autora para produzir efeito de sentido relacionado à denúncia das condições de produção, de heterogeneidade do sujeito e de dispersão do sentido e não é efeito do acaso.

Questionamo-nos se esses desvios produzem efeitos de sentido semelhantes ao de Lispector. Deparamo-nos também com a dúvida se esses desvios produzem efeitos de sentido identificáveis ou se produzem efeito de não-sentido.

Em nosso trabalho, conceberemos a pontuação como um fato discursivo. Os préconstruídos, que estão relacionados às formações discursivas, permitem ao leitor de um texto sem pontuação delimitar unidades de sentidos, e, assim, pontuá-lo, a fim de produzir um determinado sentido. Dependendo da ideologia a que cada leitor é assujeitado haverá a mobilização de saberes discursivos diferentes, produzindo distintas leituras do texto. Dessa forma, é possível pontuar um texto sem pontuação a partir de saberes préconstruídos de determinada formação discursiva. Porém, para isso, é necessário que haja a latência do funcionamento da pontuação, ou seja, é necessário que o texto se permita pontuar, que haja unidades de sentidos identificáveis. A condição essencial para que isso aconteça é que haja assujeitamento do sujeito escrevente ao discurso. No caso de patologias, o assujeitamento pode ser parcial. 
O interdiscurso é "'todo complexo com dominante' das formações discursivas [...] submetido à lei de desigualdade-contradição-subordinação que [...] caracteriza o complexo das formações ideológicas" (PÊCHEUX, 1975, p. 162). O interdiscurso é, tal como o inconsciente, desprovido de pontuação. Isso se deve pelas suas naturezas heterogêneas e contraditórias. É interessante notar que a irrupção dessas duas instâncias no texto afeta a pontuação, tanto no seu uso quanto em sua ausência.

Propomos pensar a pontuação, na análise dos textos dos pacientes psicóticos, como o represamento do interdiscurso. Cada sinal de pontuação é pensado como um obstáculo que conteria fúria do interdiscurso. A violência de suas águas deve-se ao nonsense, à contradição, à dispersão, à heterogeneidade que o habitam. Porém, esses obstáculos não são como pedras que podem ser apenas jogadas para que se barre a passagem da água. Os sinais de pontuação, que trabalham na contenção do interdiscurso, possuem um duplo funcionamento discursivo: tanto no nível histórico quanto no sintático.

O funcionamento da pontuação tem em vista a "normalização" do sentido, que ocorre pela delimitação de unidades de sentido no interdiscurso a partir do filtro da formação discursiva, ou seja, vincula um sentido a sua repetibilidade. Ao criar univocidade do sentido, afasta a materialidade textual do non-sense do real.

\begin{abstract}
ANÁLISE
Analisamos, na perspectiva da Análise do Discurso, a pontuação realizada por um paciente psicótico. Para isso, optamos por pensar a questão da pontuação a partir de fragmentos de textos. Em relação aos fragmentos que possuem pontuação, nosso recorte terá como ponto norteador a ocorrência:
\end{abstract}

1. Tanto da pontuação que produz um efeito de resistência perante os sentidos pré-estabelecidos - dessa forma, considerada indício de tangenciamento do real;

2. quanto da pontuação que vincula os sentidos do texto a pré-construídos que não dão conta daquilo que se quer expressar - surgindo assim esse "outro" sentido que não comporta uma repetibilidade discursiva. Isso ocorre porque há uma resistência perante o ato de simbolizar.

Analisaremos as sequências discursivas de referência (sdr) 1 e 2, extraídas de textos do paciente psicótico $\mathrm{V}$, do sexo masculino, de 27 de setembro de 2006, a fim de compreendermos o tangenciamento do real e a irrupção do interdiscurso na esfera da pontuação.

Sdr1: A MINHA VIZINHA LÁ PELOS ANOS 1973, UMA MENINA QUE UM DIA QUEBROU UM VASO MING DO ORIENTE, FOI COLOCADA NA FEBEM POR CAUSA DISSO. PELOS PRÓPRIOS PAIS, NÃO BASTANDO AINDA FORAM ENCOMODAR OS VIZINHOS ENCLUSIVE EU. ${ }^{9}$

\footnotetext{
${ }^{9}$ Os textos estão escritos em caixa alta para ser fiel ao fato de terem sido escritos em letra de forma e não ser possível diferenciar letra maiúscula de letra minúscula.
} 
Como afirmamos, a pontuação é um gesto de interpretação e, por esse motivo, está assujeitada à ideologia. Orlandi (2005) ensina que a pontuação produz um efeito de unidade que apaga o gesto de incompletude da linguagem. Porém, na sdr1, percebemos outro funcionamento da pontuação: ao invés de administrar, ela está tornando explícita a incompletude inerente à linguagem.

Na sdr1, há uma voz passiva, como podemos observar no recorte a seguir:

[minha vizinha] foi colocada na FEBEM [pelos próprios pais]

Porém, o sintagma "pelos próprios pais" aparece apenas na frase seguinte. Nesta frase, este sintagma não desempenha nenhuma função gramatical ou de sentido. O ponto final da primeira frase da sdr1 não desempenha sua função de fechar discursivamente uma frase, na medida em que não produz uma fixação de sentido. Após o ponto final, a frase não está completa, os sentidos vinculados a ela estão ainda se estabelecendo. $O$ ponto final que está sendo analisado, mimetiza as regras de pontuação, mas não consegue desempenhar nenhuma função discursiva que conseguiria trabalhar as questões de sentido do texto.

Orlandi (2005) ensina que "a pontuação aparece onde a continuidade falta" (ORLANDI, 2005, p. 121). Porém, na sdr 1, pela própria construção de voz passiva, não há a necessidade de um ponto final.

O ponto final, que deveria funcionar como uma delimitação que exclui tudo que não está na frase sob seu orquestramento, acaba evidenciando a fragmentação inerente ao discurso escrito. Também não desempenha o papel de delimitação, de fechamento. Ao não produzir um efeito de fechamento, esse sinal de pontuação opacifica a invasão do interdiscurso no intradiscurso, isso resulta num texto com o efeito de não sentido do interdiscurso.

A pontuação, em seu funcionamento corriqueiro, administra a incompletude da linguagem, na medida em que "fabrica a normalidade semântica do mundo, a organização do texto, a aparência de uma relação unívoca entre pensamento/mundo/linguagem, um sentido para um sujeito" (ORLANDI, 2005, p. 117). Porém, na sdr 1, a pontuação está fazendo o trabalho oposto. Ou seja, está evidenciando a incompletude da linguagem e a heterogeneidade do discurso e, dessa forma, destituindo do mundo uma normalidade semântica, que é fabricada pelos efeitos de unidade, homogeneidade e completude.

O ponto final é, portanto, um vestígio de falha no assujeitamento do paciente que está escrevendo o texto. Não é um desconhecimento das regras de pontuação, porque, pelos demais textos desse mesmo paciente, percebemos que ele está a par dessas regras. Não se apresenta como uma transgressão das normas, porque não produz efeitos de sentido múltiplos. Como nos mostra Lisbôa, em Clarice Lispector, o sinal de pontuação é usado de forma criativa e serve para que o leitor possa refletir e produzir seus próprios sentidos no texto. Observamos que, diferentemente dos textos de psicóticos que tangenciam o real, o texto de Lispector, apesar de transgredir as normas da pontuação, não modifica seu funcionamento - o que permite que os seus leitores produzam sentidos 
nos textos da autora. Os textos dos pacientes, ao denunciarem o real, silenciam seus leitores, não permitindo, assim, que eles produzam sentidos. Em textos em que há vestígios do real, não é possível a construção de um corpo discursivo que simularia efeito de autoria, na medida em que são textos que rompem com a repetibilidade discursiva, ou seja, em que se produz efeito de não-sentido. ${ }^{10}$

Por estar desempenhando um funcionamento inverso daquele que se espera, acreditamos que a pontuação estudada no recorte anterior é um vestígio do tangenciamento do real pela linguagem. A partir do presente estudo, compreendemos que as características linguageiras do tateamento do real num texto são as seguintes: opacificação da incompletude da linguagem, invasão pelo interdiscurso e efeito de silenciamento do leitor.

Orlandi (1992) mostra que o silêncio é condição da significação e que disso resulta a incompletude da linguagem. Porém, há funcionamentos na linguagem que produzem efeito de completude: "a pontuação é uma violência simbólica necessária: um mecanismo que administra nossa relação à incompletude da linguagem" (ORLANDI, 1992, p. 116). O tangenciamento do real modifica o funcionamento da pontuação: ao invés de camuflar, os sinais de pontuação ou sua ausência explicitam a incompletude da linguagem. Isso ocorre pela característica do real de não se inscrever no simbólico.

O interdiscurso é o lugar da dispersão, da heterogeneidade e da contradição dos sentidos, ou seja, o lugar do non-sense. Nas formações discursivas, os já-ditos se estabelecem como produtores de efeito de sentido homogêneo e uno. Num texto, os jáditos estão vinculados às formações discursivas, porque "o próprio de toda formação discursiva é dissimular, na transparência do sentido que nela se forma, a objetividade material contraditória do interdiscurso" (PÊCHEUX, 1975, p. 162). É o efeito de transparência do sentido que permite a leitura de um texto. Quando o interdiscurso invade um texto, ele reflete na materialidade escrita o efeito de não sentido, silenciando assim qualquer tipo de leitura.

Para a Análise do Discurso, o texto é um objeto aberto que permite uma pluralidade de leituras. Ou seja, "nem uma só, nem infinitas, mas possíveis leituras" (INDURSKY, 2003, p. 189). É nessa pluralidade que o sujeito-leitor se inscreve. Como ensina Indursky: o "sujeito-leitor, ao praticar a leitura o faz identificando-se com [...] [o] sujeito-histórico" (INDURSKY, 2003, p. 189). Dessa forma, as possíveis leituras de um texto ocorrem devido aos laços discursivos que esse estabelece com as formações discursivas: "uma mesma sequência discursiva, ao mudar de domínio de saber, passa a participar de outra família parafrástica, inserindo-se em outra matriz de sentido e produzindo, por consequência, um efeito de sentido necessariamente diverso". (INDURSKY, 2003, p. 191).

Frente a um texto, o sujeito-leitor relaciona-o às formações ideológicas e discursivas a que está assujeitado. No entanto, frente a um texto em que há o tangenciamento do real, como é o caso de alguns textos que constituem nosso arquivo discursivo, o texto perde o vínculo com a materialidade histórica, e, por causa dessa não

${ }^{10}$ É necessário ressaltar que estamos falando do texto em particular e não da capacidade do escrevente de produzir um texto com efeito de autoria. Em outros estudos vemos psicóticos estabelecendo efeito de autoria, Borba-Rodegher (2011). 
possível identificação com as formações discursivas, o sujeito-leitor fica à mercê do efeito de silenciamento ${ }^{11}$. Tudo isso se deve ao fato de o texto não ser uma materialidade discursiva, na medida em que não estabelece relação com o sentido historicamente determinado. O tangenciamento do real rompe o vínculo da materialidade escrita com as formações discursivas, porque o real não estabelece relação com os já-ditos, não é determinado ideologicamente, não tem vínculo social ou histórico e não estabelece nenhum efeito de sentido para o interlocutor. Ou seja, produz-se no texto, pela tentativa de capturar o real, o não-sentido.

Abaixo, um esquema que mostra o tateamento do real no texto analisado:

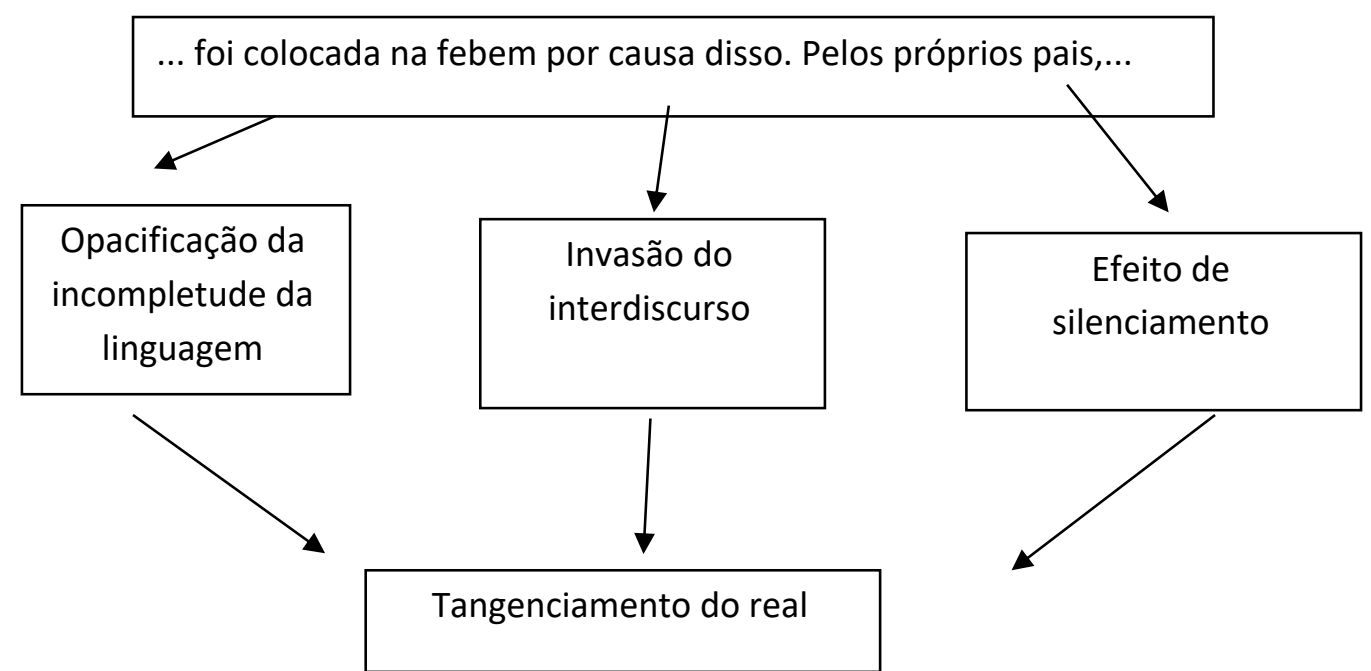

\section{llustração 1: Características linguageiras do tateamento do real no texto em análise}

A seguir, estudaremos a sdr2, que é um texto do mesmo escrevente, de 31 de maio de 2006.

\section{Sdr2:}

1 LONGE LEVAM OS PASSOS, O CAMINHO COM CURVAS,

2 PASSOS, CALÇADAS, ESTRADAS À ALGUM LUGAR ONDE SE

3 ACEMELHA A MESMA, OUTRO CAMINHO FORA DO MESMO

4 LUGAR, QUE NÃO É SÓ O MESMO, ONDE TEMOS VARIOS

5 A OPINIÃO É DIRIGIDA PELO MESMO.

Há, na sdr 2, a produção do efeito de não-sentido. Esse efeito ocorre não pela pontuação, mas pela organização dos pré-construídos no texto. Como nos ensina Leandro-Ferreira (2000),

a fuga dos enunciados, as brechas e deslizes que eles manifestam não devem ser imputados a enganos dos locutores, ou a falhas de desempenho no domínio da língua; mas, sim, a um traço próprio à

\footnotetext{
${ }^{11}$ Historicamente, a psicose gera um efeito de silenciamento no interlocutor. Tanto é verdade que, é pela não compreensão, não identificação do dito, que a família do paciente procura ajuda na medicina. E a psiquiatria busca os sintomas pela fala. Se os textos de psicóticos, na Literatura, geram outros efeitos de sentido é devido à diferenciação do sujeito-leitor que se apresenta para ler esses textos.
} 
organização singular da língua que não exclui nem rejeita o que escapa a suas próprias leis de formação. Em outros termos: o que falta ou que excede são constitutivos da estrutura, como fatos linguísticos, incontornáveis. (LEANDRO-FERREIRA, 2000, p. 94-95).

O texto em análise reflete o equívoco inerente à língua, porque, apesar de ser construído a partir de uma relação lógica entre as palavras (passos, caminhos, calçadas, lugar, direção), não produz uma unidade de sentido. Isso se deve a uma falha no assujeitamento do escrevente ao discurso, porque o sentido não está na língua, mas nas relações discursivas. O interdiscurso invade esse texto sem passar pelo filtro das formações discursivas. Nessas condições, o sujeito leitor fica à mercê do efeito de silenciamento, pois para ele ficam vedadas as interpretações e as relações intertextuais.

É uma característica inerente a um texto que tangencia o real a ausência do funcionamento da pontuação, até mesmo quando há uma pontuação aparentemente bem realizada, como ocorre na sdr2.

Percebemos, na sdr2, que há uma pontuação que mimetiza os ensinamentos da escola. Na linha 1 , há a sinalização de uma pausa. Na linha 2 , há uma enumeração em que todos os elementos são separados por vírgulas. $O$ último elemento da enumeração não é separado do resto da frase por vírgula. Na linha 4, a oração adjetiva explicativa está separada por vírgulas. Na linha 5, há a utilização de um ponto final. $\mathrm{O}$ escrevente recorre a um tipo textual apresentado pela escola, a poesia. Na perspectiva formal do texto, podemos dizer que o discurso da escola ecoa na sdr2, pela utilização das vírgulas para enumeração, separação; o ponto final para finalizar as frases; e o formato de poesia do texto. Porém, essa pontuação não produz um efeito de "normalidade" de sentido no texto. Os sinais de pontuação, na sdr2, mimetizam o uso prescrito da pontuação, ou seja, o paciente utiliza formalmente as regras de pontuação, mas o funcionamento discursivo da pontuação está ausente. A apropriação da pontuação implica assujeitamento discursivo. Pontuar é delimitar sentidos e isso só é possível quando se está assujeitado a formações discursivas. As pontuações, na sdr2, não realizam a barragem do interdiscurso nem o estancamento do real.

Podemos ver a opacificação da incompletude da linguagem no ponto final da sdr1, em que tal ponto não produz um efeito de fechamento, e, dessa forma, se opacifica a invasão do interdiscurso no intradiscurso. $O$ texto analisado perde os efeitos de unidade, homogeneidade e completude. $\mathrm{O}$ efeito de silenciamento está relacionado ao fato de o real não estabelecer relação com o sentido, nem com o interdiscurso, nem com os já-ditos. Não há determinação histórica no real, nem vínculo social ou histórico e não estabelece efeitos de sentido entre os interlocutores. Essas características do tangenciamento do real nos mostram que a escrita do impossível modifica tanto o funcionamento da pontuação quanto o funcionamento do discurso. Essa modificação se deve à natureza do real, resistente à simbolização e pela natureza do interdiscurso, contraditório e heterogêneo. $\mathrm{O}$ tangenciamento do real mostra indícios da natureza do real e do interdiscurso, porém sem nunca os inscrever no texto. 


\section{CONCLUSÃO}

Não se trata de ensinar pontuação para que o paciente consiga produzir efeito de sentido no texto. Apesar de as regras de pontuação, que representam um saber que pertence ao discurso da escola, estarem presentes no texto analisado, há falha no assujeitamento do paciente a esse discurso. A falha ocorre porque a pontuação é apenas formal e não desempenha um trabalho sobre o discurso. Há mimesis da pontuação nesse discurso, mas não apropriação do funcionamento discursivo da pontuação. Em diversos momentos, no arquivo de textos do paciente $\mathrm{V}$, percebemos que o escrevente utiliza as regras prescritas dos sinais de pontuação: porém, como percebemos nos textos estudados, há momentos em que fica evidente a diferença entre mimetizar e apropriar-se do funcionamento da pontuação; a exemplo do que podemos ver no ponto final do recorte FOI COLOCADA NA FEBEM POR CAUSA DISSO. PELOS PRÓPRIOS PAIS. A mimesis é suscetível ao erro e a apropriação está relacionada à produção de efeitos de sentido nos textos.

Pontuar é uma forma de organizar o discurso. Assim, é intrínseco a seu funcionamento o assujeitamento às formações ideológicas e discursivas. Portanto, os sinais de pontuação não apenas marcam pausas, melodias, entonações, etc., eles também refletem um assujeitamento ideológico, ao selecionar sentidos a partir de uma formação ideológica. Mimetizar o aspecto formal da pontuação não garante a um texto a produção de efeitos de sentido, de unidade e de coerência, como podemos ver na sdr2. Há, na sdr2, uma sequência lógica de palavras e uma pontuação que mostra as regras gramaticais, mas o interdiscurso invade o texto sem passar pelos filtros das formações discursivas.

$\mathrm{Na}$ análise dos fragmentos pontuados, percebemos que o tangenciamento do real ocorre junto com vestígios de falhas no funcionamento discursivo do paciente. A Psicanálise nos ensinou que, por não atravessar o estágio do Édipo, o psicótico não entra na linguagem e na cultura. Podemos constatar, através das nossas análises, que há também uma falha no assujeitamento ao discurso. $\mathrm{O}$ real não se inscreve no discurso e, dessa forma, é esta falha que permite seu tateamento pela língua ${ }^{12}$. A mimesis da pontuação, como podemos ver na análise da sdr2, nos mostra uma característica dessa falha do assujeitamento, que é a possibilidade de imitação das regras, mas sem sua apropriação propriamente dita.

Apesar de a falha do assujeitamento na psicose ser estrutural, o tangenciamento do real não está presente em todas suas manifestações linguageiras. Isso ocorre porque, embora seja falha, há traços de inscrição do psicótico no discurso, como nos mostram estudos a respeito da referência e da incisa na fala do psicótico ${ }^{13}$.

\footnotetext{
${ }^{12} \mathrm{O}$ tangenciamento do real também pode ser observado no discurso do neurótico. Porém, nesse caso, é uma falha passageira, denunciando a incompletude do sujeito.

${ }^{13}$ Como vimos em Borba (2006), o psicótico, "por ter uma estruturação subjetiva diferenciada, passa por um processo de interpelação ideológica diferente daquela percorrido pelo neurótico. A falha na interpelação resulta em um discurso que vacila entre normalidade, em determinados momentos, e a desestruturação, em outros. Apesar da desestruturação das formulações, o discurso do esquizofrênico continua ancorado nos discursos sociais. Conforme podemos perceber nas análises das incisas, os referentes produzidos em outros discursos mantêm sua configuração original, não permitindo, assim, que outras referências sejam estabelecidas na cena enunciativa". (BORBA, 2006, p. 118).
} 
A escrita que se produz pelo tangenciamento do real - que na verdade é a escrita de uma impossibilidade - apresenta características diferentes daquelas estudadas pelos estudiosos da escrita, porque possui outro funcionamento no nível do discurso. Porém, é necessário ressaltar que, tanto a escrita do tangenciamento do real quanto a escrita cotidiana, são previstas pelo funcionamento da língua.

O tangenciamento do real pode se manifestar tanto na presença quanto na ausência de pontuação ${ }^{14}$, porque ele não está relacionado com os sinais de pontuação ou com as regras de utilização desses sinais prescritas pelos gramáticos. A escrita dessa impossibilidade está relacionada com o funcionamento da pontuação, ou seja, com o mecanismo discursivo da pontuação de seleção e de organização dos saberes préconstruídos a partir do filtro das formações discursivas.

A mudança do funcionamento da pontuação, como podemos observar em nossa análise, ativa este outro funcionamento da linguagem: o tangenciamento do real. Essa escrita do impossível é prevista pela linguagem, mas não em seu funcionamento cotidiano. As características observadas na análise para o tangenciamento do real, no nível da pontuação, são a opacificação da incompletude da linguagem, a invasão do interdiscurso e o efeito de silenciamento do leitor.

\section{REFERÊNCIAS}

BORBA, P. O funcionamento da referência na perspectiva da Análise do Discurso. Porto Alegre, UFRGS, 2006.

BORBA-RODEGHER, P. A escrita na Psicose. Porto Alegre, UFRGS, 2011.

CHACON, L. Ritmo da escrita. São Paulo: Martins Fontes, 1998.

CALIL, E. Autoria: a criança e a escrita de histórias inventadas. Londrina: Eduel, 2004.

DARMON, M. Guillemets. In: JOURNÉES DE L'ASSOCIATION FREUDIENNE INTERNATIONALE. La Ponctuation. Paris: Centre Hospitalier Sainte Anne, 1997. FREUD, S. (1924). A perda da realidade na neurose e na psicose. Edição Standard Brasileira das obras completas de Sigmund Freud v. XIX. Rio de Janeiro: Imago Editora, 1988.

GADET, F.; PÊCHEUX, M. (1981). A língua inatingível. Campina: Pontes, 2004.

INDURSKY, F. Lula lá: estrutura e acontecimento. Organon, Porto Alegre, v. 17, n. 35 , 2003.

LACAN, J. (1957-1958). De uma questão preliminar a todo tratamento possível da psicose. In _ _ Escritos. Rio de Janeiro: Jorge Zahar, 1998.

. (1964) Seminário 11: os quatro conceitos fundamentais da psicanálise. Rio de Janeiro: Jorge Zahar Editor, 1998.

. (1973) Seminário 20: mais, ainda. Rio de Janeiro: Jorge Zahar Editor, 1985.

LEANDRO-FERREIRA, M. C. Da ambigüidade ao equívoco a resistência da língua nos limites da sintaxe e do discurso. Porto Alegre: Editora da Universidade, 2000.

LEITE, N. Psicanálise e Análise do Discurso: o acontecimento na estrutura. Rio de Janeiro: Campo Matêmico, 1994.

\footnotetext{
${ }^{14}$ Estudamos o tangenciamento do real pela ausência de pontuação em BORBA-RODEGHER (2011).
} 
LISBÔA, N. A pontuação do silêncio: uma análise discursiva da escritura de Clarice Lispector. 2008. Dissertação (Mestrado em Letras) - Programa de Pós-graduação em Letras, Universidade Federal do Rio Grande do Sul, Porto Alegre, 2008.

MILNER, J.-C. O amor da língua. Porto Alegre: Artes Médicas, 1987.

ORLANDI, E. P. As formas do silêncio: no movimento do sentido. São Paulo: Unicamp, 1992.

Discurso e Texto: formulação e circulação dos sentidos. São Paulo: Pontes, 2005. PÊCHEUX, M. (1975) Semântica e discurso: uma crítica à afirmação do óbvio. Campinas: Unicamp, 1995.

(1983). A Análise do discurso: três épocas. In GADET, F e HAK, T. Por uma análise automática do discurso: uma introdução à obra de Michel Pêcheux. Campinas: Editora da Unicamp, 1997.

Ouverture du colloque. In: CONEIN, B. et al. Matérialités discursives. Lille: Presses Universitaires de Lille, 1981.

PLON, M. Análise do discurso (de Michel Pêcheux) vs Análise do inconsciente. In INDURSKY, F.; LEANDRO FERREIRA, M. C. Michel Pêcheux e Análise do Discurso: uma relação de nunca acabar. São Carlos: Claraluz, 2007.

Artigo recebido em: abr. de 2020.

Aprovado e revisado em: jun. de 2020.

Publicado em: julho de 2020.

Para citar este texto:

BORBA-RODEGHER, Patrícia Laubino. O Real pelo Viés da Pontuação. Entremeios [Revista de Estudos do Discurso, ISSN 2179-3514, on-line, www.entremeios.inf.br], Seção Estudos, Programa de Pós-Graduação em Ciências da Linguagem (PPGCL), Universidade do Vale do Sapucaí (UNIVÁS), Pouso Alegre (MG), vol. 21, p. 211-227, jan. - jun. 2020.

DOI: http://dx.doi.org/10.20337/ISSN2179-3514revistaENTREMEIOSvol21pagina211a227 